\title{
Conserved expression and functions of PDE4 in rodent and human heart
}

\author{
Wito Richter - Moses Xie - Colleen Scheitrum • \\ Judith Krall • Matthew A. Movsesian • \\ Marco Conti
}

Received: 21 September 2010/Revised: 17 November 2010/Accepted: 1 December 2010/Published online: 16 December 2010

(C) The Author(s) 2010. This article is published with open access at Springerlink.com

\begin{abstract}
PDE4 isoenzymes are critical in the control of cAMP signaling in rodent cardiac myocytes. Ablation of PDE4 affects multiple key players in excitation-contraction coupling and predisposes mice to the development of heart failure. As little is known about PDE4 in human heart, we explored to what extent cardiac expression and functions of PDE4 are conserved between rodents and humans. We find considerable similarities including comparable amounts of PDE4 activity expressed, expression of the same PDE4 subtypes and splicing variants, anchoring of PDE4 to the same subcellular compartments and macromolecular signaling complexes, and downregulation of PDE4 activity and protein in heart failure. The major difference between the species is a fivefold higher amount of non-PDE4 activity in human hearts compared to rodents. As a consequence, the effect of PDE4 inactivation is different in rodents and humans. PDE4 inhibition leads to increased phosphorylation of virtually all PKA substrates in mouse cardiomyocytes, but increased phosphorylation of only a restricted number of proteins in human cardiomyocytes. Our findings suggest that
\end{abstract}

Electronic supplementary material The online version of this article (doi:10.1007/s00395-010-0138-8) contains supplementary material, which is available to authorized users.

W. Richter $(\bowtie) \cdot$ M. Xie $\cdot$ C. Scheitrum $\cdot$ M. Conti

Department of Gynecology, Obstetrics, and Reproductive

Sciences, Center for Reproductive Sciences,

University of California San Francisco, Box 0556,

513 Parnassus Avenue, San Francisco, CA 94143-0556, USA

e-mail: richterw@obgyn.ucsf.edu

J. Krall · M. A. Movsesian

Cardiology Section, Veterans Affairs Salt Lake City Health Care

System and the Departments of Internal Medicine (Cardiology)

and Pharmacology, University of Utah School of Medicine,

Salt Lake City, USA
PDE4s have a similar role in the local regulation of cAMP signaling in rodent and human heart. However, inhibition of PDE4 has 'global' effects on cAMP signaling only in rodent hearts, as PDE4 comprises a large fraction of the total cardiac PDE activity in rodents but not in humans. These differences may explain the distinct pharmacological effects of PDE4 inhibition in rodent and human hearts.

Keywords cAMP $\cdot 3^{\prime}, 5^{\prime}$-Cyclic nucleotide phosphodiesterase · PDE4 - Human heart · Heart failure

\author{
Abbreviations \\ $\beta$ AR $\quad \beta$-Adrenoceptor \\ $\mathrm{Ca}_{\mathrm{v}} 1.2 \quad$ L-type calcium channel \\ DHCM Dividing human cardiomyocytes \\ GPCR G protein-coupled receptor \\ IDC Idiopathic dilated cardiomyopathy \\ IP Immunoprecipitation \\ ISO Isoproterenol \\ PDE $\quad 3^{\prime}, 5^{\prime}$-Cyclic nucleotide phosphodiesterase \\ PKA cAMP-dependent protein kinase \\ PLB Phospholamban \\ RyR2 Ryanodine receptor \\ SERCA Sarcoendoplasmic reticulum calcium ATPase
}

\section{Introduction}

cAMP is a ubiquitous second messenger that transduces the action of numerous hormones and neurotransmitters into cellular responses. In the heart, cAMP mediates the inotropic, chronotropic and lusitropic effects of $\beta$-adrenoceptor $(\beta \mathrm{AR})$ stimulation by catecholamines, as well as the effects 
of many other hormones that act through $\mathrm{G}$ protein-coupled receptors (GPCRs), including prostaglandins, glucagon and serotonin [42, 65, 66, 83, 85].

In order to maintain the specificity of the diverse hormone responses, cAMP signaling is compartmentalized [43, 49]. Proteins involved in cAMP signaling, such as GPCRs, adenylyl cyclases and cAMP effectors such as the cAMPdependent protein kinase (PKA) and its downstream targets, are organized into physically and functionally distinct multiprotein complexes, an arrangement that increases both efficiency and specificity of signaling. Cyclic nucleotide phosphodiesterases (PDEs), the enzymes that hydrolyze and inactivate cAMP, are critical components of these signaling complexes, serving to limit access to and to finely regulate cAMP levels within these compartments [9]. Eleven families of phosphodiesterases, defined based on their kinetic and pharmacologic properties, have been identified [9]. The enzymes belonging to the PDE4 family are particularly important in the control of cAMP signaling in rodent cardiac myocytes. PDE4 isoforms control the PKA-mediated regulation of $\beta_{1}$ - and $\beta_{2} \mathrm{ARs}$, L-type calcium channels $\left(\mathrm{Ca}_{\mathrm{v}} 1.2\right)$, cardiac ryanodine receptors (RyR2), the phospholamban/ sarcoplasmic reticulum calcium ATPase (PLB/SERCA) complex and troponin I [19, 26, 35, 39, 41, 58, 63, 84]. Several of these signaling proteins have been shown to anchor PDE4 isoenzymes in signaling complexes.

The PDE4 family consists of four genes, PDE4A to PDE4D. By the use of different promoters and alternative splicing, each PDE4 gene is expressed as multiple variants. Together, more than 20 PDE4 variants are known. They differ in their regulatory properties and their subcellular localization, which is determined by variant-specific protein/protein or protein/lipid interactions [10,25]. The observation that the various signaling complexes identified in the heart exhibit a distinct preference for one particular PDE4 variant or another suggests that individual PDE4 variants serve unique functions. $\beta_{1} \mathrm{AR}, \beta_{2} \mathrm{AR}$, and RyR2, for example, interact preferentially with the variants PDE4D8, PDE4D5, and PDE4D3, respectively [39, 58, 63]. PDE4 inhibition often substantially increases their PKA-dependent phosphorylation, and thereby exerts a considerable impact on the function of the associated signaling proteins in isolated cardiomyocytes in culture $[11,50,65,84]$, though the effects of acute PDE4 inhibition on cardiac performance in live animals are often subtle. PDE4 inactivation has been reported to produce a small effect on basal blood pressure and heart rate or $\beta$-adrenoceptorstimulated heart rate in animals in some studies but to have no effect in others [20-22, 34, 54, 61, 73, 82]. In addition, PDE4 inactivation generally does not affect inotropy under basal conditions. However, PDE4 inactivation has been shown to potentiate the inotropic responses of cardiac tissue preparations to serotonin, glucagon, catecholamines or PDE3 inhibitors in mouse, rat, guinea pig, rabbit and dog ex vivo suggesting that PDE4 is more critical under conditions of elevated cAMP production $[7,15,16,22,29,32,34,54,68$, 77, 82]; see [57] for a review.

The limited effects of PDE4 inactivation on cardiac function may attest to the capacity of the mammalian organism to compensate for loss of PDE4. It is also possible that PDE4 inactivation in different intracellular compartments may have opposing effects on cardiac performance. Whereas increased PKA phosphorylation of $\mathrm{Ca}_{\mathrm{v}} 1.2$, PLB or RyR2 resulting from PDE4 ablation may increase excitation-contraction coupling and cardiac output, the effect of increased phosphorylation of $\beta$ ARs, troponin I and perhaps other PKA substrates could counteract these effects [63]. Thus, the outcome of cAMP elevation triggered by the activation of cAMP production (such as through $\beta$-adrenergic stimulation) is functionally distinct from cAMP elevation resulting from PDE4 inactivation. The overall effect of PDE4 inactivation is not an increase in cardiac output per se. Instead, PDE4 inactivation likely removes a compensatory mechanism that normally allows cardiac myocytes to finely tune cAMP levels in different subcellular compartments. As a result, PDE4 inactivation may result in adverse cardiac effects that are uncovered under stress conditions. Pharmacologic or genetic inactivation of PDE4 potentiates adrenalin-evoked [13] or exercise-induced [39] arrhythmias in mice, and PDE4 inhibition triggers arrhythmias in a coronary artery occlusion and reperfusion model in rabbits [24]. In addition, genetic inactivation of PDE4D in mice triggers development of a late-onset cardiomyopathy and increased mortality after cardiac infarction [39].

Whereas much has been learned about the unique roles of PDE4 isoenzymes in cardiac physiology and pathophysiology in experimental animals, little is known about the role of PDE4 in the human heart. With respect to at least one other phosphodiesterase, PDE5, marked differences in expression between mouse and human hearts have been reported [75], thus raising questions regarding the applicability of the mouse model to pathophysiology and therapeutics in humans [38, 45, 60, 75]. We, therefore, examined the expression patterns of PDE4 variants in the hearts of mice, rats, and humans, their subcellular targeting and changes in expression levels between healthy and failing hearts as well as the effect of PDE4 inactivation on PKA-mediated phosphorylation patterns.

\section{Methods}

\section{Heart tissue}

Human myocardium was obtained from the left ventricular free walls of the hearts of organ donors for whom no suitable recipients were identified on the United Network 
for Organ Sharing (UNOS) waiting list at the time of organ procurement ('normal' hearts) and of the explanted hearts of patients with idiopathic dilated cardiomyopathy (IDC) undergoing cardiac transplantation (failing hearts) as described previously [52]. The use of human tissues was approved by the University of Utah internal review board and conformed to the principles outlined in the 1964 Declaration of Helsinki. All animal studies were performed according to the guidelines of the National Institutes of Health Guide for the Care and Use of Laboratory Animals published by the US National Institutes of Health (NIH Publication No. 85-23, revised 1996) and were approved by the Institutional Animal Care and Use Committee of the University of California San Francisco.

\section{Immunoprecipitation}

Heart tissues were homogenized in $50 \mathrm{mM}$ Tris- $\mathrm{HCl}(\mathrm{pH}$ 7.4), $1 \mathrm{mM}$ EDTA, $0.2 \mathrm{mM}$ EGTA, $150 \mathrm{mM} \mathrm{NaCl}$, $1.34 \mathrm{mM} \beta$-mercaptoethanol, $10 \%$ glycerol, $0.2 \% \mathrm{NP}-40$ (nonylphenoxypolyethoxylethanol), $1 \mu \mathrm{M}$ microcystin-LR, Complete protease inhibitor cocktail (Roche Diagnostics), and $1 \mathrm{mM}$ AEBSF (4-(2-aminoethyl)-benzenesulfonyl fluoride hydrochloride). Extracts were precleared with $50 \mu \mathrm{l}$ ProteinG-Sepharose for $1 \mathrm{~h}$, followed by immunoprecipitation with $30 \mu \mathrm{l}$ ProteinG-Sepharose and $2 \mu \mathrm{g}$ of the respective antibody for $4 \mathrm{~h}$.

Cell culture

Dividing human cardiomyocytes (DHCMs) were obtained from PromoCell GmbH and cultured in PromoCell's Myocyte Growth Medium. Ventricular cardiomyocytes were isolated from the excised hearts of 1-2-day-old neonatal mice and subsequently cultured as described previously [63].

PDE activity assay

PDE activity was measured using $1 \mu \mathrm{M}$ cAMP as substrate as described previously [63]. The activity for PDE1, PDE2, PDE3 and PDE4 was defined as the fraction of total PDE activity inhibited by vinpocetine $(20 \mu \mathrm{M})$, Bay 60-7550 (100 nM), cilostamide $(1 \mu \mathrm{M})$ and rolipram $(10 \mu \mathrm{M})$, respectively.

Adenylyl cyclase activity assay

Adenylyl cyclase activity was measured as described previously [28].

Antibodies

The following antibodies were used: rabbit anti-sarcomeric actinin (Abcam), calsequestrin and phospholamban
(Affinity BioReagents), PKA substrate (Cell Signaling), Ser16-phospho-phospholamban (Upstate), $\beta_{1}$ AR (Santa Cruz Biotechnology), mouse anti-sarcomeric actinin, antiFlag and $\alpha$-tubulin (Sigma-Aldrich), antibodies against individual PDE4A and PDE4B variants (Fabgennix), PDE4D (ICOS). PAN-PDE4 as well as PDE4 subtype- and splice variant-selective antibodies have been described previously [64].

Immunocytochemistry

Human or mouse myocardium was frozen in Tissue-Tek ${ }^{\circledR}$ O.C.T. (Optimal Cutting Temperature) Compound (Sakura Finetek) and sectioned at $7 \mu \mathrm{m}$. Slides were fixed with $4 \%$ paraformaldehyde for $20 \mathrm{~min}$ followed by a 5-min incubation with $0.5 \%$ Triton X-100 in PBS. Slides were blocked for $60 \mathrm{~min}$ at room temperature with PBS containing $10 \%$ goat serum, $1 \%$ BSA, and $0.1 \%$ Triton $\mathrm{X}-100$. Slides were then incubated for $2 \mathrm{~h}$ with primary antibodies diluted 1:500 in blocking buffer. After three washes with blocking buffer, the sections were incubated for $1 \mathrm{~h}$ with fluorescein isothiocyanate (FITC)-labeled and Cy3-labeled secondary antibodies, washed three times with blocking buffer and mounted in VectaShield mounting medium (Vector Laboratories).

Detailed methods are included in the supplementary material.

\section{Results}

A conserved expression pattern of PDE4 subtypes and variants detected in human and rodent myocardium

As the first step in exploring the role of PDE4 in the human heart, we compared levels of PDE4 activity in preparations of human left ventricular myocardium and in comparable preparations from mouse and rat hearts. When normalized to total protein, PDE4 activity was present at similar levels of 17-24 $\mathrm{pmol} / \mathrm{min} / \mathrm{mg}$ protein in mouse, rat and human heart (Fig. 1a). There were major differences, however, in the levels of PDE4 activity relative to total cellular phosphodiesterase activity. PDE4 contributes a much larger portion of the total PDE activity in mouse and rat heart (32 and 52\%, respectively) than in human heart (8\%) (Fig. 1b). This difference is attributable to the fivefold higher total cAMPhydrolytic activity in humans relative to rodents, which results from the high level expression of several non-PDE4 subtypes, including PDE1, PDE2 and PDE3, in humans. The higher amount of total PDE activity present in human heart compared to rodents is not accompanied by a similarly higher level of adenylyl cyclase activity (Supplementary Fig. 1). As a result, there is a higher ratio of cAMP-hydrolytic activity to 
Fig. 1 Expression of PDE subtypes in mouse, rat and human heart. Detergent extracts prepared from mouse, rat or failing human hearts were subjected to PDE activity assays in the presence or absence of subtype-selective PDE inhibitors using $1 \mu \mathrm{M}$ cAMP as substrate. Total PDE activity is defined as the activity measured in the absence of inhibitors, whereas PDE1, PDE2, PDE3 and PDE4 are defined as the fraction of total PDE activity inhibited by vinpocetine $(20 \mu \mathrm{M})$, Bay 60-7550 (100 $\mathrm{nM})$, cilostamide $(1 \mu \mathrm{M})$ and rolipram $(10 \mu \mathrm{M})$, respectively. Data are presented as specific $\mathrm{PDE}$ activity in $\mathrm{pmol} / \mathrm{min} / \mathrm{mg}$ in (a) and as \% of total activity in (b) and represent the mean \pm SEM of four experiments. c Cryosections of human myocardium were double-stained with antibodies against sarcomeric actinin (red) and either anti-PAN-PDE4 antibodies or normal $\mathrm{IgG}$ as a control (green)
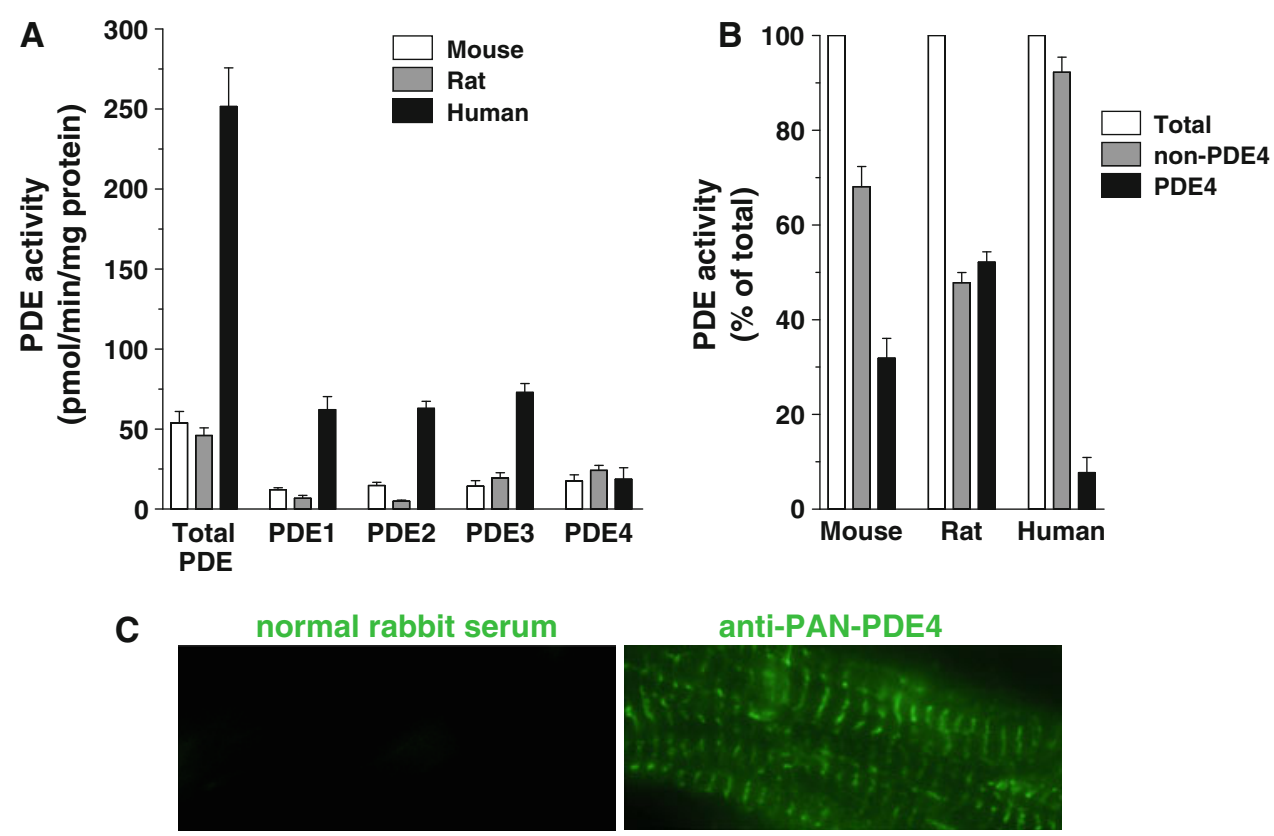

anti-sarcomeric actinin

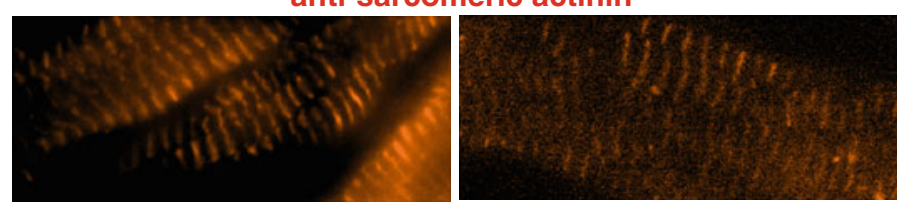

merge

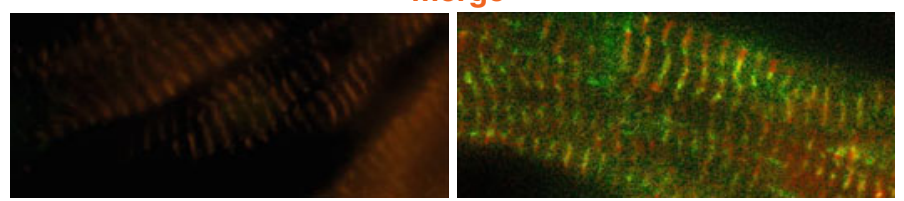

total cAMP-generating activity in human hearts compared to rodent hearts.

Next, we determined the intracellular localization of PDE4 in cardiac muscle by immunocytochemistry. PDE4 localizes to the Z-band of cardiomyocytes in human (Fig. 1c) and mouse heart (data not shown), suggesting that PDE4 activity detected in heart extracts is due to the expression of PDE4 in the cardiomyocytes and that PDE4 acts in defined subcellular compartments of these cells.

These observations, which may suggest a conservation of PDE4 function between these species, led us to investigate patterns of PDE4 expression, localization, and function in more detail in rodent and human heart. To determine the contribution of the different PDE4 subtypes to the total PDE4 activity expressed, we performed immunoprecipitations (IPs) with PDE4 subtype-selective antibodies followed by measurement of PDE activity in the IP pellets. The specificity of these antibodies for the targeted PDE4 subtypes was confirmed in experiments using preparations from the respective knock-out mice (Supplementary Fig. 2). Using this approach, three PDE4 subtypes, PDE4A,
PDE4B and PDE4D, could be immunoprecipitated from preparations of mouse, rat and human hearts (Fig. 2). Earlier reports suggested that PDE4C $\mathrm{mRNA}$ and protein is not expressed in the heart [37]; thus, PDE4C was not investigated. PDE4A, PDE4B and PDE4D are expressed at comparable levels in rodents, whereas PDE4D appears to be the predominant form expressed in human heart.

Each of the four PDE4 genes is expressed as multiple variants. As individual variants are thought to have specific roles in a cell, we wished to determine whether the same PDE4 variants are expressed in the hearts of mice, rats and humans. A predominant band for PDE4A, migrating at 105-110 kDa, was identified in mouse hearts (Fig. 3a, top left panel). The majority of this band is attributable to PDE4A10, whereas a small fraction is due to PDE4A5, as determined by migration of this band in SDS/PAGE and pull-down experiments with PDE4A variant-selective antibodies (Supplementary Fig. 3). This finding is consistent with reports that mRNA for PDE4A10 is found at high levels in the heart [62]. An immunoreactive band consistent with the migration of PDE4A10 was similarly detected in 


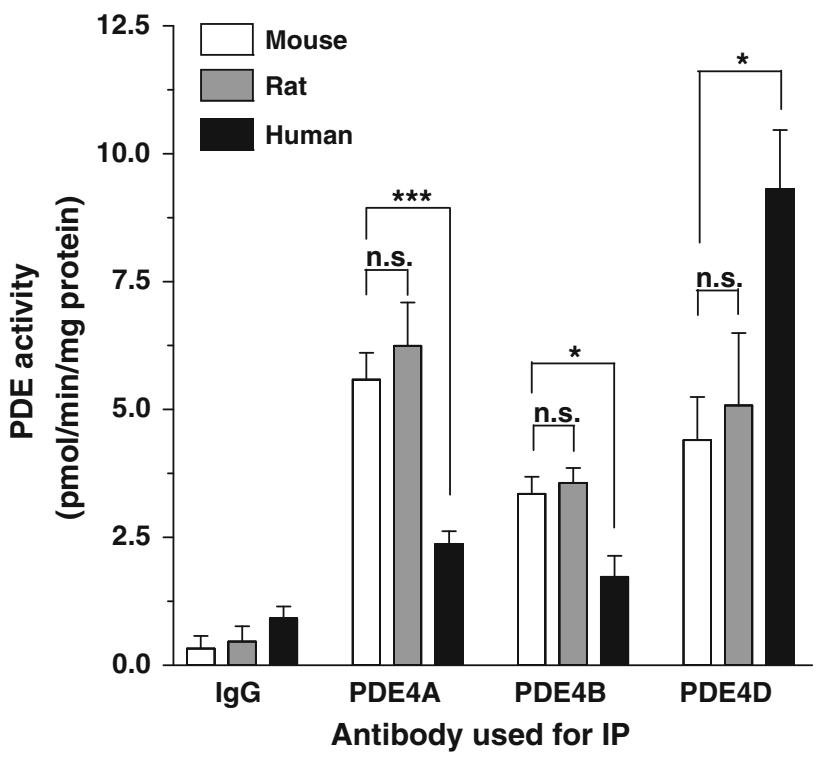

Fig. 2 Expression of PDE4 subtypes in rodent and human heart. Detergent extracts prepared from mouse, rat or failing human hearts were subjected to immunoprecipitations with PDE4 subtype-selective antibodies or normal IgG as a control. PDEs recovered in the IP pellet were detected by PDE activity assay using $1 \mu \mathrm{M}$ cAMP as substrate. Data are presented as mean \pm SEM of at least three experiments. n.s. (not significant) indicates $p>0.05 ; * p<0.05 ; * * * p<0.001$

rat and human heart suggesting that PDE4A10 is the predominant PDE4A variant expressed in all three species (Fig. 3a, top panels).
A similar picture emerged when comparing the PDE4B immunoblot signals (Fig. 3a, middle panels). A major signal for PDE4B is detected at $\sim 95 \mathrm{kDa}$ in mouse heart, and immunoreactive bands of the same migration were found in rat and human tissue. Migration of the PDE4B band detected in heart tissues is consistent with that of recombinant PDE4B3 and the expression of PDE4B3 in heart tissue was confirmed with variant-selective antibodies (Supplementary Fig. 4).

Finally, for PDE4D, a similar pattern of immunoblot signals was detected in the three species (Fig. 3a, bottom panels). A predominant band is detected at 91-95 kDa, consistent with the migration of PDE4D3, PDE4D8, or PDE4D9 [64]. Upon longer exposure of the blots, a minor band of higher molecular weight is detected. Its migration corresponds to that of PDE4D5 or PDE4D7 [64]. To distinguish between the variants of similar migration, we carried out immunoprecipitations with splice variantselective antibodies. As shown in Fig. 3b, PDE4D3, PDE4D5, PDE4D8 and PDE4D9, but not PDE4D4, are detected in mouse, rat and human heart (top, middle and bottom panels). Both the similar pattern of immunoreactive bands for PDE4A, PDE4B and PDE4D in SDS/PAGE (Fig. 3a) as well as the expression of similar PDE4 variants as detected by immunoprecipitations (Supplementary Figs. 3 and 4, and Fig. 3b) suggest that the same splice variants of PDE4 are expressed in mouse, rat and human heart.
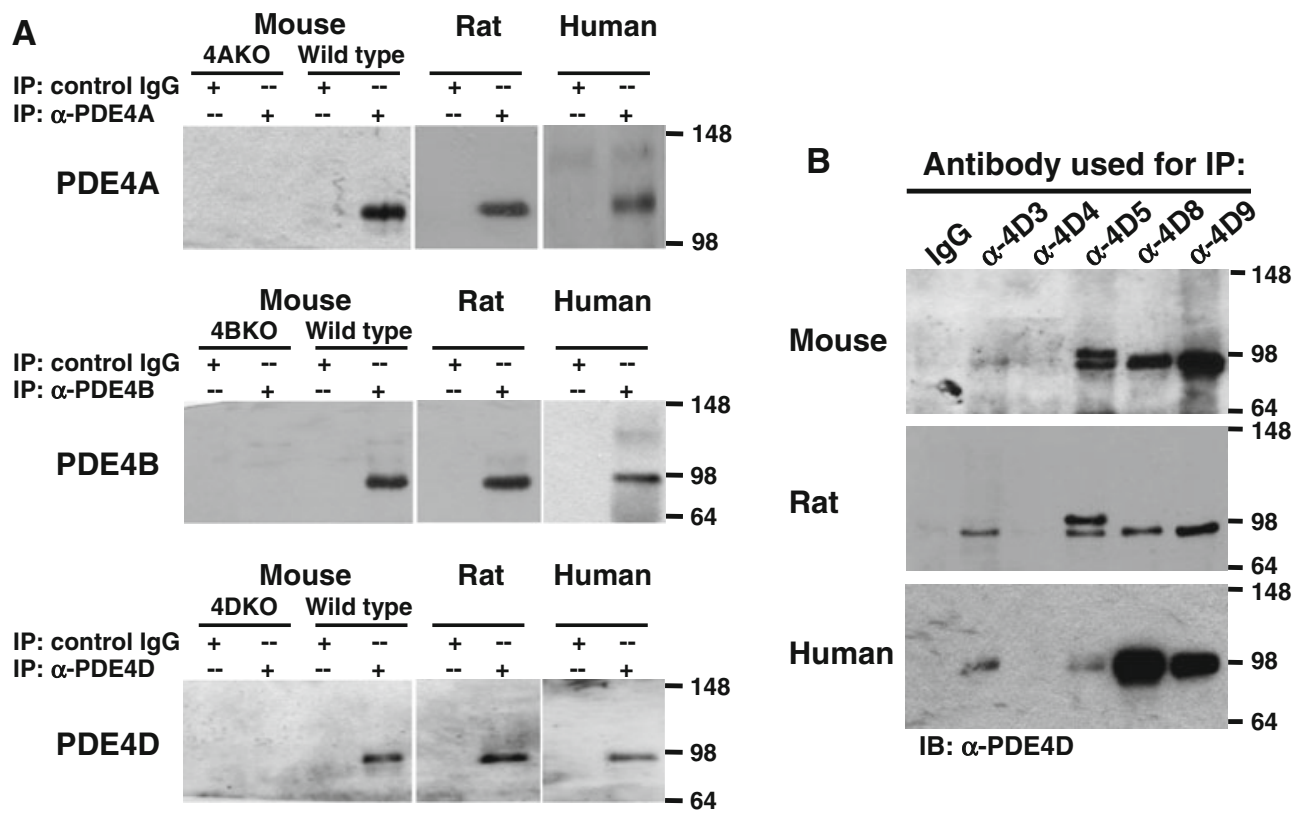

Fig. 3 Expression of PDE4 splice variants in rodent and human heart. Detergent extracts prepared from mouse, rat or failing human hearts were subjected to immunoprecipitations with normal $\mathrm{IgG}$ as a control or a PDE4 subtype-selective or b PDE4D variant-selective antibodies. PDE4 proteins recovered in the IP pellets were detected by Western blotting using PAN-PDE4 antibodies. All Western blots shown are representative of experiments performed three times 


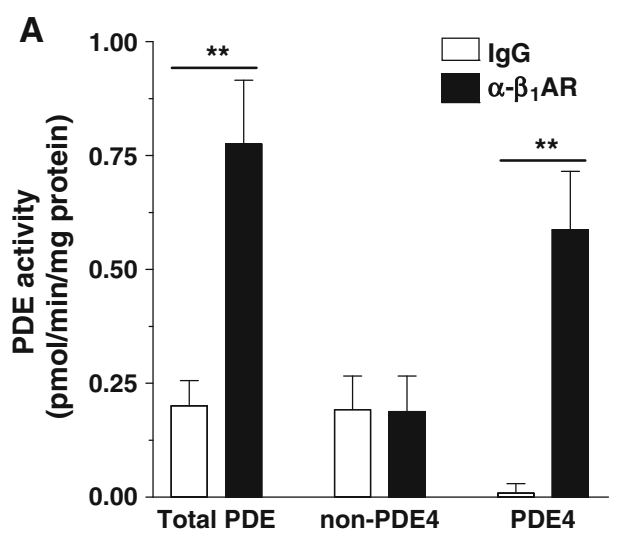

Fig. 4 Detection of macromolecular signaling complexes involving PDE4 in the human heart. Detergent extracts prepared from human failing myocardium were immunoprecipitated with normal $\mathrm{IgG}$ as a control or with antibodies generated against $\mathbf{a}$ the $\beta_{1}$-adrenergic receptor $\left(\beta_{1} \mathrm{AR}\right)$ or $\mathbf{b}$ phospholamban (PLB). PDE activity recovered in the IP pellets was then measured in the absence or presence of the

Detection of macromolecular signaling complexes involving PDE4 in the human heart

Individual PDE4 variants are often engaged in unique macromolecular signaling complexes. Having found similar patterns of expression of PDE4 isoforms and variants in rodent and human hearts, we tested whether these variants are localized to the same macromolecular signaling complexes. A complex formed between the $\beta_{1} \mathrm{AR}$ and PDE4D has been reported in mouse cardiac myocytes [63]. As shown in Fig. 4, the only cAMP-hydrolytic activity specifically co-immunoprecipitated with an antibody against the endogenous $\beta_{1} \mathrm{AR}$ from human myocardium is PDE4 (see Supplementary Fig. 5 for a characterization of the $\beta_{1} \mathrm{AR}$ antibody used). This suggests that PDE4, while representing only a small fraction of total cAMP-hydrolytic activity in human myocardium, may have a predominant role in regulating cAMP content in the vicinity of the $\beta_{1} \mathrm{AR}$. As a second target, we investigated the PLB/SERCA2 signaling complex, which has been shown to bind PDE4D in mouse heart [35]. Immunoprecipitations using an anti-PLB antibody pull down a significant amount of PDE activity from human heart extracts, indicating that PDEs are localized to this complex as well (Fig. 4b). Approximately half of the cAMP-hydrolytic activity that co-immunoprecipitates with phospholamban is PDE4, suggesting that it is one of several phosphodiesterases that regulate cAMP content in this compartment. Its presence in defined signaling complexes suggests that PDE4 is likely to serve similar functions in controlling cAMP signaling in discrete microdomains, such as in the vicinity of the $\beta_{1} \mathrm{AR}$ as well as PLB in both rodents and humans. The presence of PDE4 in these signaling complexes is also in agreement with its subcellular localization to the Z-band of human cardiomyocytes as shown in Fig. 1c.

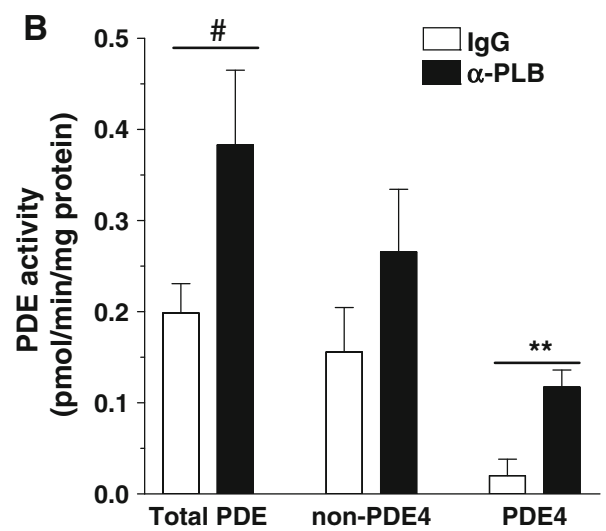

PDE4-selective inhibitor rolipram $(10 \mu \mathrm{M})$. All data are presented as mean \pm SEM of at least three experiments. Cyclic AMP-PDE activity in PLB IPs was significantly greater compared to IgG control using paired $t$ test $\left({ }^{\#} p<0.05\right)$, whereas the $p$ value was 0.054 using unpaired $t$ test. $* * p<0.01$ (unpaired $t$ test)

PDE4 expression is reduced in failing human heart

A recent report demonstrated reduced levels of PDE4 activity and protein in a rat model of cardiac hypertrophy [1]. We wished to determine if similar differences exist between normal and failing human heart. In agreement with previous reports, we found no difference in total PDE activity between extracts prepared from normal hearts and the explanted hearts from patients with idiopathic dilated cardiomyopathy (IDC) (Fig. 5a) [3, 53, 57, 71, 75, 78]. Next, we determined the levels of PDE4 subtypes by immunoprecipitation with subtype-selective antibodies. As shown in Fig. 5b and c, activities for PDE4A and PDE4D were significantly lower in failing hearts compared to normal controls. Differences in PDE4B could not be conclusively determined because of the low expression level of PDE4B in human heart. Reduced activity of PDE4 subtypes is due to changes in protein levels as demonstrated for PDE4D in Fig. 5d and e. This reduction in PDE4D protein expression may be responsible for the reduced levels of PDE4D associated with the RyR2 in failing human hearts which was reported previously [39]. The parallel downregulation of cardiac PDE4 in an animal model of pathologic cardiac hypertrophy and in failing human hearts suggests that changes in PDE4 levels may be functionally significant in the development of heart failure.

PDE4 affects local but not global cAMP levels in human cardiomyocytes

As PDE4 expression patterns and the assembly of macromolecular signaling complexes involving PDE4 appear conserved among mice, rats and humans, we expected inactivation of PDE4 to have similar effects in 
Fig. 5 Comparison of PDE4 expression in failing and normal human heart. Detergent extracts prepared from human myocardium were subjected to immunoprecipitations with PDE4 subtype-selective antibodies. PDE activity in the detergent extracts used as IP input (a) as well as the PDE activity recovered in IP pellets (b/c) was measured using $1 \mu \mathrm{M}$ cAMP as substrate. d/e Immunoblot analysis of PDE4D expression in pooled samples of normal and failing human heart. Quantification of the PDE4D immunoblot intensity of the individual samples of normal and failing human myocardium is shown in (e). All data were obtained from four samples of normal heart and seven samples of failing myocardium from patients with idiopathic dilated

cardiomyopathy (IDC) and are presented as mean \pm SEM. Age and gender of individual tissue donors are reported in Supplementary Table 1. $* p<0.05$
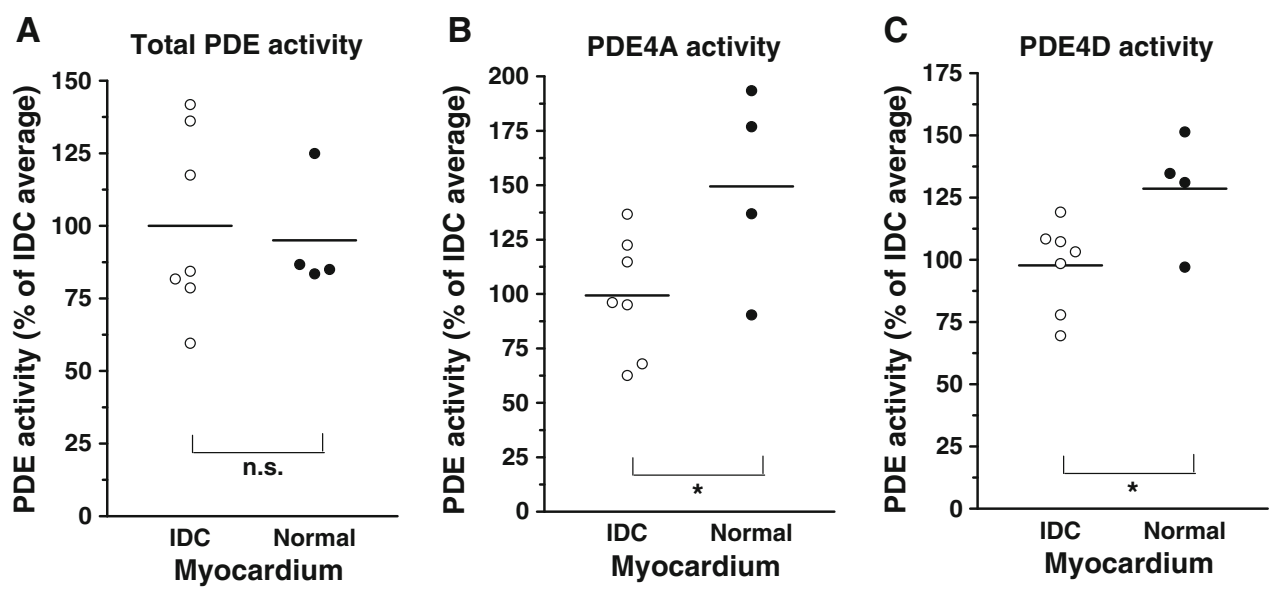

PDE4D protein levels
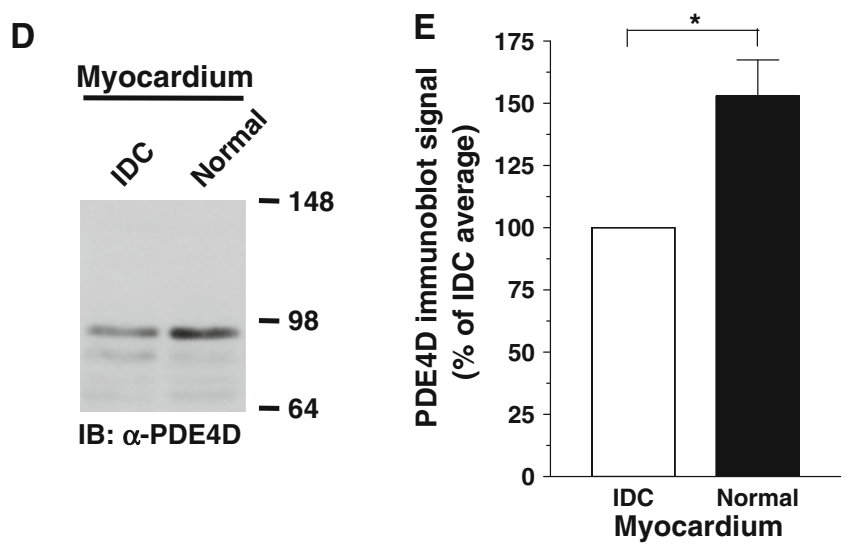

microdomains of cAMP signaling in all three species. However, as inactivation of PDE4 removes only a small fraction of the total cellular PDE activity in human heart but a substantial amount of total cellular PDE activity in rodent hearts (Fig. 1b), we expected PDE4 inhibition to affect 'global' cAMP signaling to a much greater degree in rodent hearts. To test this, we studied the effect of PDE4 inhibition on PKA-dependent phosphorylation patterns in dividing human cardiomyocytes (DHCMs) in culture. These cells exhibit a pattern of PDE subtypes similar to that of human heart tissue (Fig. 6a), with PDE4 representing a minor fraction of total PDE activity. In response to $\beta$-adrenergic stimulation with isoproterenol (ISO), a large number of proteins is phosphorylated by PKA as detected in immunoblots using a PKA substrate antibody (Fig. 6b). Pretreatment with the PDE4 inhibitor rolipram has no obvious effect on PKA phosphorylation levels of the majority of proteins, either under basal conditions or after ISO treatment. This observation concurs with the idea of PDE4 having little impact on global cAMP signaling. However, the phosphorylation of several individual PKA substrates was increased upon PDE4 inhibition either under basal conditions or after ISO stimulation as shown on the example of the 135 and $20 \mathrm{kDa}$ bands in Fig. 6b-d, respectively.
This confirms a role of PDE4 in regulating phosphorylation of specific PKA substrates in human cardiomyocytes.

In contrast, in neonatal mouse cardiomyocytes, in which PDE4 represents $>50 \%$ of total cAMP-hydrolytic activity [63], inhibition of PDE4 increased the level of phosphorylation of a large number of PKA substrates under basal conditions and further potentiated PKA phosphorylation levels induced by ISO (Fig. 6e, f). We were unable to identify any bands of PKA substrates that were increased by $\beta$-adrenergic stimulation without being increased by treatment with rolipram or further elevated by combined treatment with ISO and rolipram. The increased phosphorylation levels of this large number of bands suggest that, in addition to specific microdomains of signaling, PDE4 inactivation in mouse cardiomyocytes elevates cAMP levels and PKA activity globally, thus, likely also affecting compartments that are not specifically controlled by localized PDE4.

\section{Discussion}

cAMP signaling in cardiac myocytes is compartmentalized [43, 49]. Owing to differences in their intracellular 
Fig. 6 Effect of PDE4 inactivation on phosphorylation of PKA substrates in human and mouse cardiomyocytes. a Detergent extracts prepared from dividing human cardiomyocytes (DHCMs) in culture were subjected to PDE activity assays in the presence or absence of PDE subtypeselective inhibitors using a substrate concentration of $1 \mu \mathrm{M}$ cAMP. Data represent the average of three experiments. Cultures of dividing human cardiomyocytes (b-d) or mouse neonatal cardiomyocytes $(\mathbf{e} / \mathbf{f})$ were treated with or without the PDE4 inhibitor rolipram $(10 \mu \mathrm{M})$ for $5 \mathrm{~min}$ followed by a 5 -min treatment with isoproterenol (ISO; $1 \mu \mathrm{M}$ ). Similar amounts of detergent extracts prepared from these cell cultures were separated by SDS/ PAGE and phosphorylation of PKA substrates was subsequently detected using a PKA substrate-selective antibody. b Representative immunoblot of the PKA phosphorylation pattern in human cardiomyocytes. c/d Immunoblots and quantification of immunoblot signal intensity for two PKA substrates in human cardiomyocytes that migrate at $135 \mathrm{kDa}(\mathbf{c})$ and $20 \mathrm{kDa}(\mathbf{d})$, respectively. e/f Representative Western blot and quantification of PKA phosphorylation patterns in neonatal mouse cardiomyocytes. $* p<0.05$; $* * p<0.01$
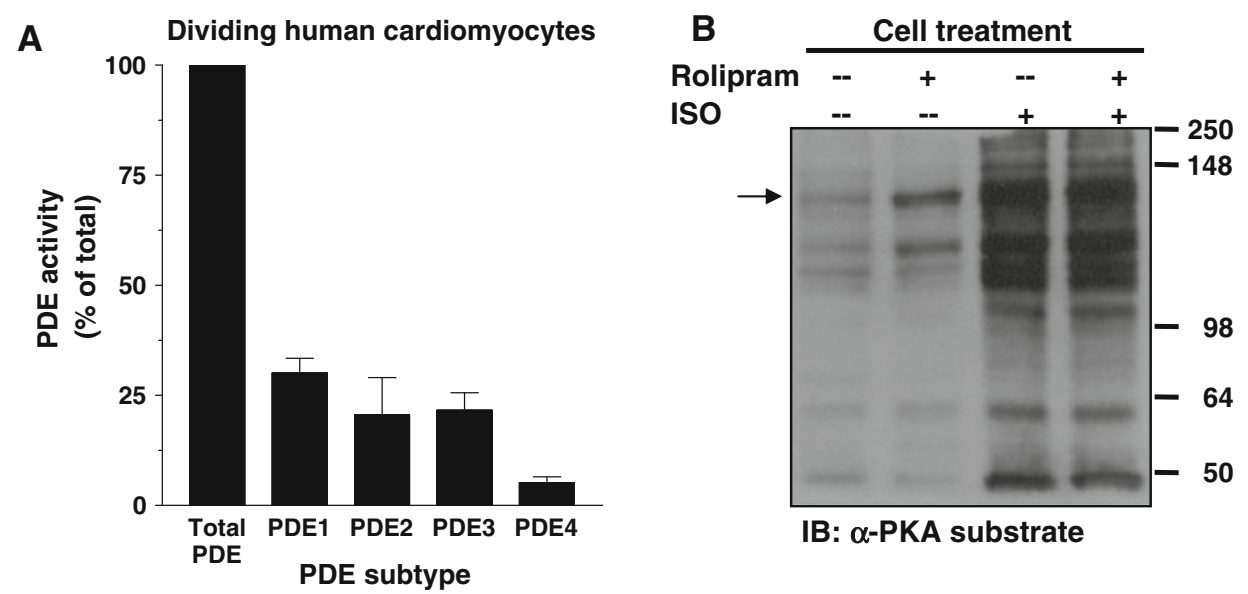

IB: $\alpha$-PKA substrate
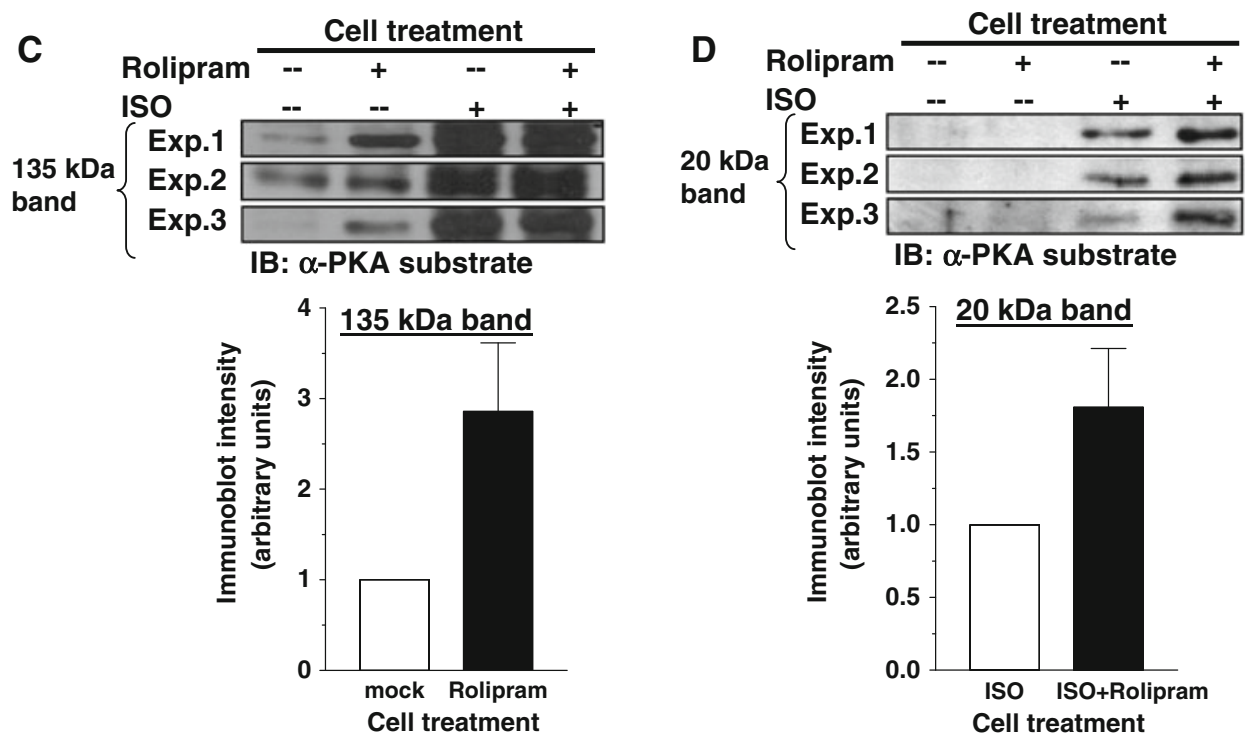

E

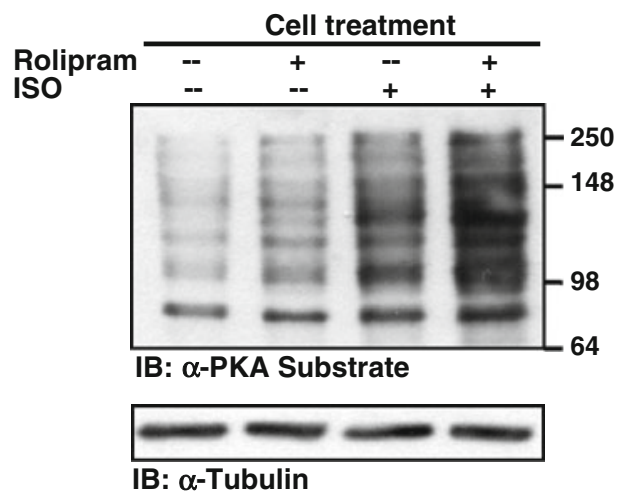

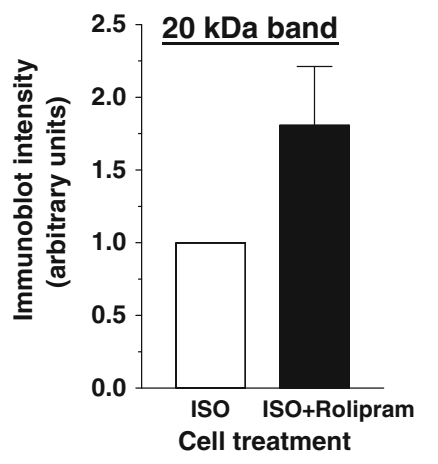

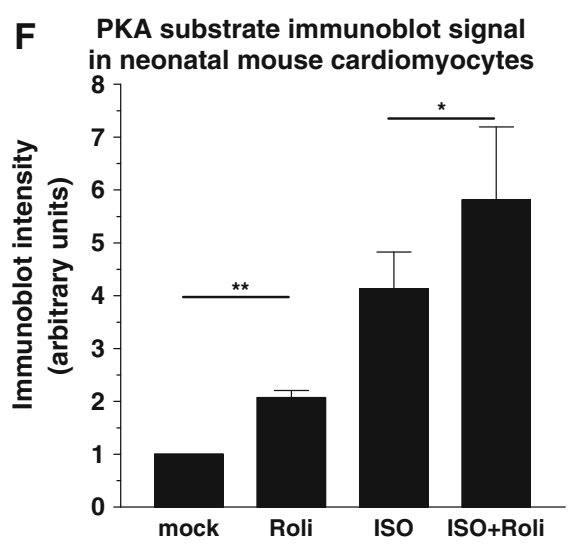

localization, individual phosphodiesterases contribute to this compartmentalization by regulating cAMP content, and hence cAMP-dependent protein phosphorylation, in individual compartments. As a corollary, the functional significance of a particular PDE subtype is not solely determined by its expression level in a given cell or tissue, and PDE subtypes that represent a minor fraction of total
PDE activity might have important roles by acting locally in critical microdomains of cAMP signaling. As a consequence of this compartmentalization, not all cAMP produced is exposed to degradation by the total cellular cAMP-PDE activity. Indeed, this is a prerequisite for cAMP signaling to occur at similar, physiologically effective concentrations even though total PDE activity is 
five times higher in human compared to rodent hearts (Fig. 1), whereas cAMP production by adenylyl cyclases is essentially the same (Supplementary Fig. 1).

Over the last decade, much progress has been made in uncovering the functions of individual PDE4 variants in the rodent heart [26]. The picture that has emerged is that individual PDE4 variants localized to discreet microdomains of cAMP signaling control the activity of individual proteins such as $\beta \mathrm{ARs}, \mathrm{Ca}_{\mathrm{v}} 1.2, \mathrm{RyR} 2$, and PLB/SERCA within these domains $[35,39,41,58,63,84]$. In addition, PDE4 isoforms, cumulatively, may also control cAMPmediated signaling at a global level in cardiac myocytes. However, with the exception of the RyR2/PDE4D complex, the individual functions of PDE4s have not been confirmed in human tissues, and the general applicability of observations made in rodents to humans has been uncertain because of the observation that PDE4 inhibitors affect a large fraction of the cAMP-hydrolytic activity in the hearts of mice and rats (as well as other relevant animal models such as dog) but only a minor fraction of the cAMP-hydrolytic activity in human hearts (Fig. 1b) [1, 41, 46, 53, 63, 69, 7982]. The experiments described here address these issues. We show that PDE4 activity is present in human hearts at levels similar to those found in mouse and rat hearts (Fig. 1). There is a strong conservation of expression patterns of PDE4s among the three species with respect to subtypes and splicing variants (Figs. 2, 3). Furthermore, in humans, PDE4 is tethered to macromolecular signaling complexes that are known to involve the same enzymes in the rodent heart, including the phospholamban/SERCA2 and the $\beta_{1} \mathrm{AR}$ complexes (Fig. 4). These findings suggest that PDE4 isoforms are likely to have roles in the local control of cAMP signaling in human hearts that are similar to their roles in rodent hearts. These results, when added to observations that PDE4D binds RyR2 and controls the PKA-mediated phosphorylation of this channel in both mouse and human heart [39] and that PDE4 regulates $\beta$-adrenoceptor-stimulated L-type calcium channel currents $\left(I_{\mathrm{Ca}}\right)$ in rodent, rabbit, as well as human cardiomyocytes [31, 35, 41], document the roles of PDE4 isoforms in human as well as rodent hearts. How PDE4 regulation of these signaling proteins impacts contractility of human ventricular myocytes remains to be determined at the mechanistic level. PDE4 inhibition has been shown to produce a minor increase in inotropy in human atrial trabeculae [74] and to potentiate serotoninstimulated inotropy in human left ventricular trabeculae under concomitant inhibition of PDE3 [2] suggesting the involvement of PDE4 variants in controlling excitationcontraction coupling in humans as well as in rodents. However, other studies did not detect an effect of PDE4 inhibition on the positive inotropic effects mediated through 5-HT4 receptors in human atrium and $\beta_{1} \mathrm{ARs}$ and $\beta_{2} \mathrm{ARs}$ in human atrium as well as ventricle $[6,8,14,33]$.
Whereas PDE4 expression levels and patterns are similar among mice, rats and humans, our findings also demonstrate a major difference between rodent and human hearts: while PDE4 accounts for $30-50 \%$ of the total measured cAMP-hydrolytic activity in mouse and rat hearts, it accounts for less than $10 \%$ of this activity in human hearts, owing to the much higher levels of other phosphodiesterases in the latter. This finding is in agreement with prior studies showing that the vast majority of cAMP-hydrolytic activity in human ventricular myocardium is attributable to isoforms belonging to the PDE1, PDE2 and PDE3 families [18, 59, 76]. This difference between humans and rodents may have biological consequences that are uncovered when PDE4 is inactivated, as PDE4 isoforms, cumulatively, may also control cAMPmediated signaling at a global level in cardiac myocytes. PDEs may contribute to the generation of cAMP compartments by acting as barriers for cAMP diffusion [30] or as local sinks for cAMP [72]. One could, therefore, envision that the higher amount of PDE activity present in the human heart would promote a tighter control of cAMP compartmentalization. Since PDE4 represents the predominant fraction of total cAMP-hydrolytic activity in rodent heart, its inhibition may limit PDE barrier function and allow broad cAMP diffusion. In addition, it would result in accumulation of a substantial amount of global cAMP because the remaining non-PDE4s may not be able to fully compensate for the loss of PDE4 activity. Indeed, rolipram treatment has been reported to increase total cAMP levels as measured by radioimmunoassay in neonatal mouse cardiac myocytes [84]. A similar effect of PDE4 inhibition on total cAMP levels would not be expected in human heart because of the large amount of non-PDE4 activity, which could compensate for the loss of PDE4 on the global scale. Indeed, by comparing the effects of PDE4 inactivation on human and mouse cardiomyocytes (Fig. 6), we observe that a plethora of PKA substrates is hyper-phosphorylated upon PDE4 inhibition in mouse cardiomyocytes, whereas only a limited number of PKA phosphorylations is potentiated by PDE4 inhibition in human cells. These distinct patterns of PKA phosphorylations are in line with the idea that PDE4 inactivation has local effects on cAMP signaling in both species, whereas global effects on cAMP signaling are evident only in rodent cardiomyocytes (Fig. 7).

With the onset of cardiac disease, the cAMP signaling cascade undergoes dramatic changes. Although catecholamine levels are high, the $\beta \mathrm{AR} / \mathrm{Gs}$ protein/adenylyl cyclase axis of cAMP production is downregulated and desensitized [5, 44, 51]. Several studies have explored whether reduction in cAMP production in diverse models of murine cardiac disease are accompanied by changes in cAMPhydrolytic capacity. While there are some differences 


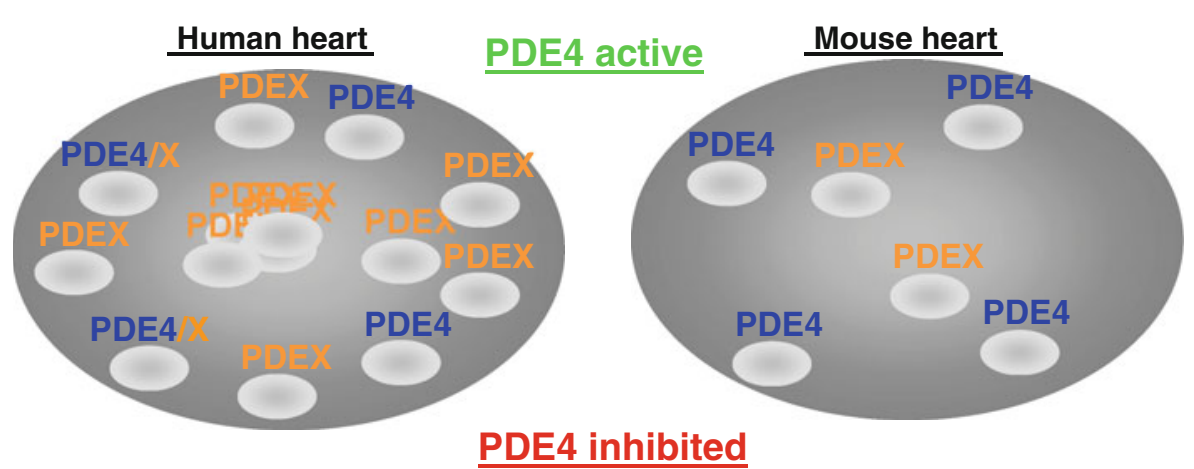

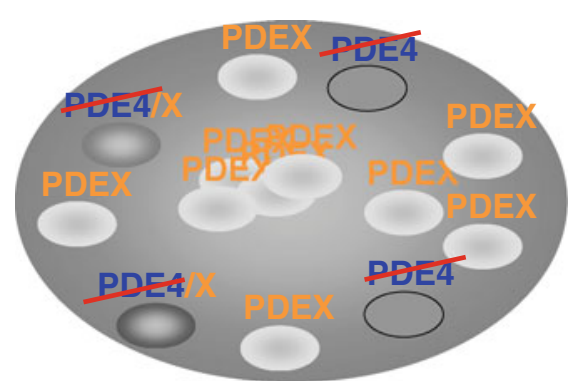

Fig. 7 Illustration of the role of PDE4 in rodent and human cardiomyocytes and the effect of PDE4 inhibition. A given subcellular domain in rodent or human cardiac myocytes is indicated as a large ellipse with its gray shading representing cAMP levels within this domain. This subcellular domain contains several localized pools of PDE4 as well as localized pools of non-PDE4 (PDEX) which are more frequent in human cardiomyocytes due to the higher levels of non-PDE4 expression compared to rodents (see Fig. 1). Localized pools of PDEs deplete microdomains of signaling of cAMP, thus acting as a sink for cAMP. These are indicated as small ellipses beneath the PDE4/PDEX label and their lighter color illustrates the reduced cAMP levels in these microdomains. Upon PDE4 inactivation, microdomains that had previously been depleted of cAMP by PDE4 in human heart, now assume cAMP levels of their surrounding environment (gray). In microdomains that had been controlled by both PDE4 and non-PDE4, a partial effect of PDE4 inhibition could

between disease models, the majority of studies investigating this issue reported a downregulation of protein and activity for different PDE subtypes including PDE4 [1, 12, $39,47,67,70,86$ ]; see [57] for a review. The cause of these changes is still poorly understood. According to one hypothesis, the reduction in PDE activity may initially be compensatory and aimed to increase cAMP levels and, thus, cardiac output. However, the reduced cAMP-hydrolytic capacity may result in impairment of the tight regulation of cAMP signaling and the separation of cAMP compartments and, thus, may eventually contribute to the development of heart disease. The significance of controlling cAMP compartmentation is supported by the observation that increases of cAMP levels by distinct mechanisms can have opposing effects on cardiac function. Stimulation of cAMP signaling through treatment with $\beta$-adrenergic agonists or PDE3 inhibitors, although stimulating contractility in the short term, results in increased

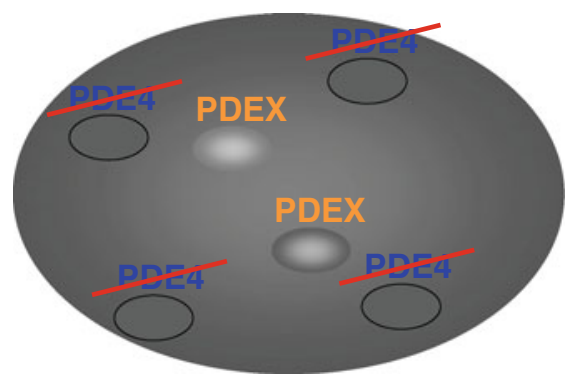

be expected. The same effect occurs in principal in mouse cardiac myocytes. However, as PDE4 inactivation has also removed a large percentage of the total PDE activity, cAMP that was previously degraded by PDE4 now accumulates in the cell resulting in higher global cAMP levels indicated as the dark shading of the large ellipse. Increase in global cAMP levels also affects cAMP signaling in microdomains that are controlled by localized non-PDE4s (PDEX). The degree to which this increase in global cAMP affects microdomains controlled by non-PDE4s will depend on the amount of nonPDE4 tethered to this compartment and whether negative feedback mechanisms, such as a PKA-mediated activation of PDE3 [56], may increase the activity of the localized non-PDE4 and thus counteract exposure to increased global cAMP levels. The increase in global cAMP levels due to PDE4 inhibition in rodent heart is not expected to occur in the human heart, because the large amount of non-PDE4 remaining in the cell will compensate for the loss of PDE4

mortality in heart failure patients. Conversely, stimulation of cAMP levels through overexpression of adenylyl cyclase 6 (AC6) is cardioprotective in mice (see [23, 40], for a review). In agreement with previous findings in a rat model of cardiac hypertrophy [1], we report here that PDE4A expression is reduced in failing human hearts compared to normal controls (Fig. 5b). Transcripts and promoter activity of PDE4A10, which we show to be the major PDE4A variant expressed, are downregulated in response to increased cAMP levels in mouse cardiomyocytes [48]. This effect is PKA-dependent and driven by a pool of cAMP that is generated by $\beta$-adrenoceptor stimulation and controlled by PDE4-dependent cAMP hydrolysis. Thus, chronically high catecholamine levels, a hallmark of heart failure, may contribute to the cAMPdependent downregulation of PDE4A in the hearts of both rodents and humans in particular at the onset of cardiac disease, at which point $\beta$ AR-dependent cAMP stimulation 
is not yet desensitized. In agreement with the reduced PDE4A levels we report, PDE4A mRNA has been shown to be reduced in patients with non-ischemic cardiomyopathy compared to non-failing hearts (GEO dataset GDS1362 [36]). The mechanisms that control PDE4D expression in the heart have not been explored thus far. It was previously shown that the amount of PDE4D3 that is associated with RyR2 is reduced in failing human hearts compared to normal controls, and this change has been proposed to contribute to dysregulation of RyR2 in heart failure [39]. Our observation that PDE4D expression levels are reduced in failing hearts (Fig. 5c-e) may suggest that the reduced levels of PDE4D associated with RyR2 in heart failure are due to lower cellular expression levels of PDE4D rather than an altered interaction of PDE4D with RyR2. However, it should be emphasized that the extent to which changes in phosphodiesterase levels contribute to the pathophysiology or represent compensatory responses is unknown.

PDE4-selective inhibitors are currently being developed as therapeutic agents for inflammatory diseases such as asthma and chronic obstructive pulmonary disease (COPD) to avoid the cardiovascular effects associated with broad-spectrum PDE inhibitors such as theophylline [27]. The observation that PDE4 inactivation can trigger arrhythmias and lead to the development of heart failure in mice raises the question of whether PDE4 inhibitor treatment may represent a risk factor for cardiac disease also in humans. Indeed, PKA-hyperphosphorylation of RyR2 as a result of reduced PDE4D levels has been proposed to promote dysregulation of this channel in both mice and humans [39]. The PDE4D gene has also been associated with increased risk of cardioembolic stroke in an Icelandic cohort [17], although studies in non-Icelanders reported variable results [55] and PDE4D in cells other than cardiomyocytes may be responsible. However, a recent 1-year trial with the PDE4 inhibitor roflumilast reported no differences in the incidence of most cardiovascular adverse events in the PDE4 inhibitor and placebo group, respectively, although atrial fibrillation was an infrequent complication reported in higher numbers in the roflumilast group compared to controls [4]. The findings of the present study suggest that PDE4 inhibition could affect local signaling events, such as in macromolecular signaling complexes that tether PDE4, similarly in both rodents and humans, but affect global cAMP signaling only in rodent heart. It is unknown whether dysregulation of local signaling events or changes in global cAMP signaling drive the adverse cardiac effects observed in rodents. If the latter is the case, our findings might explain why adverse cardiac effects reported for animals have not been observed in humans.
Acknowledgments We are indebted to Minnie Hsieh for expert advice on tissue fixation, sectioning, and immunocytochemistry and to Fang Xie for help with adenylyl cyclase activity assays. Mammalian expression vectors encoding human PDE4A10 and PDE4A11, and heart tissue from $\beta_{1} \mathrm{AR}-\mathrm{KO}$ mice were kindly provided by Drs. Miles Houslay (University of Glasgow, Scotland) and Brian Kobilka (Stanford University), respectively. This work was supported by Fondation Leducq (06CVD02 cycAMP to M.C. and M.A.M.); the National Institutes of Health (HL0927088 to M.C.); and grants from the United States Department of Veterans Affairs Medical Research Funds (to M.A.M.).

Conflict of interest The authors declare that they have no conflict of interest.

Open Access This article is distributed under the terms of the Creative Commons Attribution Noncommercial License which permits any noncommercial use, distribution, and reproduction in any medium, provided the original author(s) and source are credited.

\section{References}

1. Abi-Gerges A, Richter W, Lefebvre F, Mateo P, Varin A, Heymes C, Samuel JL, Lugnier C, Conti M, Fischmeister R, Vandecasteele G (2009) Decreased expression and activity of cAMP phosphodiesterases in cardiac hypertrophy and its impact on betaadrenergic cAMP signals. Circ Res 105(8):784-792. doi:10. 1161/CIRCRESAHA.109.197947

2. Afzal F, Andressen KW, Mork HK, Aronsen JM, Sjaastad I, Dahl CP, Skomedal T, Levy FO, Osnes JB, Qvigstad E (2008) 5-HT4elicited positive inotropic response is mediated by cAMP and regulated by PDE3 in failing rat and human cardiac ventricles. $\mathrm{Br}$ J Pharmacol 155(7):1005-1014. doi:10.1038/bjp.2008.339

3. Bethke T, Klimkiewicz A, Kohl C, von der Leyen H, Mehl H, Mende U, Meyer W, Neumann J, Schmitz W, Scholz H et al (1991) Effects of isomazole on force of contraction and phosphodiesterase isoenzymes I-IV in nonfailing and failing human hearts. J Cardiovasc Pharmacol 18(3):386-397

4. Calverley PM, Rabe KF, Goehring UM, Kristiansen S, Fabbri LM, Martinez FJ (2009) Roflumilast in symptomatic chronic obstructive pulmonary disease: two randomised clinical trials. Lancet 374(9691):685-694. doi:10.1016/S0140-6736(09)61255-1

5. Chidsey CA, Braunwald E, Morrow AG, Mason DT (1963) Myocardial norepinephrine concentration in man. Effects of reserpine and of congestive heart failure. N Engl J Med 269:653658

6. Christ T, Engel A, Ravens U, Kaumann AJ (2006) Cilostamide potentiates more the positive inotropic effects of $(-)$-adrenaline through beta(2)-adrenoceptors than the effects of (-)-noradrenaline through beta (1)-adrenoceptors in human atrial myocardium. Naunyn Schmiedebergs Arch Pharmacol 374(3):249-253. doi:10.1007/s00210-006-0119-5

7. Christ T, Galindo-Tovar A, Thoms M, Ravens U, Kaumann AJ (2009) Inotropy and L-type $\mathrm{Ca}^{2+}$ current, activated by beta1- and beta2-adrenoceptors, are differently controlled by phosphodiesterases 3 and 4 in rat heart. Br J Pharmacol 156(1):62-83. doi: 10.1111/j.1476-5381.2008.00015.x

8. Christ T, Molenaar P, Galindo-Tovar A, Ravens U, Kaumann AJ (2006) Contractile responses through Gs-coupled receptors are reduced by phosphodiesterase 3 activity in human isolated myocardium. In: Compartmentalization of cyclic AMP signalling P014, Biochemical Society Meeting, Cambridge, UK 
9. Conti M, Beavo J (2007) Biochemistry and physiology of cyclic nucleotide phosphodiesterases: essential components in cyclic nucleotide signaling. Annu Rev Biochem 76:481-511. doi:10.1146/ annurev.biochem.76.060305.150444

10. Conti M, Richter W, Mehats C, Livera G, Park JY, Jin C (2003) Cyclic AMP-specific PDE4 phosphodiesterases as critical components of cyclic AMP signaling. J Biol Chem 278(8):54935496. doi:10.1074/jbc.R200029200

11. De Arcangelis V, Soto D, Xiang Y (2008) Phosphodiesterase 4 and phosphatase $2 \mathrm{~A}$ differentially regulate $\mathrm{cAMP} /$ protein kinase a signaling for cardiac myocyte contraction under stimulation of beta1 adrenergic receptor. Mol Pharmacol 74(5):1453-1462. doi: 10.1124/mol.108.049718

12. Ding B, Abe J, Wei H, Huang Q, Walsh RA, Molina CA, Zhao A, Sadoshima J, Blaxall BC, Berk BC, Yan C (2005) Functional role of phosphodiesterase 3 in cardiomyocyte apoptosis: implication in heart failure. Circulation 111(19):2469-2476. doi:10.1161/01. CIR.0000165128.39715.87

13. Galindo-Tovar A, Kaumann AJ (2008) Phosphodiesterase-4 blunts inotropism and arrhythmias but not sinoatrial tachycardia of (-)-adrenaline mediated through mouse cardiac beta(1)adrenoceptors. Br J Pharmacol 153(4):710-720. doi:10.1038/sj. bjp.0707631

14. Galindo-Tovar A, Vargas ML, Escudero E, Kaumann AJ (2009) Ontogenic changes of the control by phosphodiesterase- 3 and -4 of 5-HT responses in porcine heart and relevance to human atrial 5-HT(4) receptors. Br J Pharmacol 156(2):237-249. doi:10.1111/ j.1476-5381.2008.00023.x

15. Galindo-Tovar A, Vargas ML, Kaumann AJ (2009) Phosphodiesterases PDE3 and PDE4 jointly control the inotropic effects but not chronotropic effects of (-)-CGP12177 despite PDE4-evoked sinoatrial bradycardia in rat atrium. Naunyn Schmiedebergs Arch Pharmacol 379(4):379-384. doi:10.1007/s00210-008-0367-7

16. Galindo-Tovar A, Vargas ML, Kaumann AJ (2010) Function of cardiac beta1- and beta2-adrenoceptors of newborn piglets: role of phosphodiesterases PDE3 and PDE4. Eur J Pharmacol 638(1-3):99-107. doi:10.1016/j.ejphar.2010.04.013

17. Gretarsdottir S, Thorleifsson G, Reynisdottir ST, Manolescu A, Jonsdottir S, Jonsdottir T, Gudmundsdottir T, Bjarnadottir SM, Einarsson OB, Gudjonsdottir HM, Hawkins M, Gudmundsson G, Gudmundsdottir H, Andrason H, Gudmundsdottir AS, Sigurdardottir M, Chou TT, Nahmias J, Goss S, Sveinbjornsdottir S, Valdimarsson EM, Jakobsson F, Agnarsson U, Gudnason V, Thorgeirsson G, Fingerle J, Gurney M, Gudbjartsson D, Frigge ML, Kong A, Stefansson K, Gulcher JR (2003) The gene encoding phosphodiesterase 4D confers risk of ischemic stroke. Nat Genet 35(2):131-138. doi:10.1038/ng 1245

18. Hambleton R, Krall J, Tikishvili E, Honeggar M, Ahmad F, Manganiello VC, Movsesian MA (2005) Isoforms of cyclic nucleotide phosphodiesterase PDE3 and their contribution to cAMP hydrolytic activity in subcellular fractions of human myocardium. J Biol Chem 280(47):39168-39174. doi:10.1074/ jbc.M506760200

19. Haworth RS, Cuello F, Avkiran M (2010) Regulation by phosphodiesterase isoforms of protein kinase A-mediated attenuation of myocardial protein kinase D activation. Basic Res Cardiol. doi: 10.1007/s00395-010-0116-1

20. Heaslip RJ, Buckley SK, Sickels BD, Grimes D (1991) Bronchial vs. cardiovascular activities of selective phosphodiesterase inhibitors in the anesthetized beta-blocked dog. J Pharmacol Exp Ther 257(2):741-747

21. Heaslip RJ, Evans DY (1995) Emetic, central nervous system, and pulmonary activities of rolipram in the dog. Eur J Pharmacol 286(3):281-290. doi:0014299995004572

22. Herzer WA, Thomas NJ, Carcillo JA, Tofovic SP, Jackson EK (1998) Effects of type IV phosphodiesterase inhibition on cardiac function in the presence and absence of catecholamines. J Cardiovasc Pharmacol 32(5):769-776

23. Ho D, Yan L, Iwatsubo K, Vatner DE, Vatner SF (2010) Modulation of beta-adrenergic receptor signaling in heart failure and longevity: targeting adenylyl cyclase type 5. Heart Fail Rev 15(5):495-512. doi:10.1007/s10741-010-9183-5

24. Holbrook M, Coker SJ (1991) Effects of zaprinast and rolipram on platelet aggregation and arrhythmias following myocardial ischaemia and reperfusion in anaesthetized rabbits. Br J Pharmacol 103(4):1973-1979

25. Houslay MD, Adams DR (2003) PDE4 cAMP phosphodiesterases: modular enzymes that orchestrate signalling cross-talk, desensitization and compartmentalization. Biochem J 370(Pt 1): 1-18. doi:10.1042/BJ20021698

26. Houslay MD, Baillie GS, Maurice DH (2007) cAMP-specific phosphodiesterase-4 enzymes in the cardiovascular system: a molecular toolbox for generating compartmentalized cAMP signaling. Circ Res 100(7):950-966. doi:10.1161/01.RES.0000261934. 56938.38

27. Houslay MD, Schafer P, Zhang KY (2005) Keynote review: phosphodiesterase-4 as a therapeutic target. Drug Discov Today 10(22):1503-1519. doi:10.1016/S1359-6446(05)03622-6

28. Jaiswal BS, Conti M (2001) Identification and functional analysis of splice variants of the germ cell soluble adenylyl cyclase. J Biol Chem 276(34):31698-31708. doi:10.1074/jbc.M011698200

29. Juan-Fita MJ, Vargas ML, Kaumann AJ, Hernandez Cascales J (2004) Rolipram reduces the inotropic tachyphylaxis of glucagon in rat ventricular myocardium. Naunyn Schmiedebergs Arch Pharmacol 370(4):324-329. doi:10.1007/s00210-004-0978-6

30. Jurevicius J, Fischmeister R (1996) cAMP compartmentation is responsible for a local activation of cardiac $\mathrm{Ca}^{2+}$ channels by beta-adrenergic agonists. Proc Natl Acad Sci USA 93(1):295-299

31. Kajimoto K, Hagiwara N, Kasanuki H, Hosoda S (1997) Contribution of phosphodiesterase isozymes to the regulation of the L-type calcium current in human cardiac myocytes. Br J Pharmacol 121(8):1549-1556. doi:10.1038/sj.bjp.0701297

32. Katano Y, Endoh M (1990) Differential effects of Ro 20-1724 and isobutylmethylxanthine on the basal force of contraction and beta-adrenoceptor-mediated response in the rat ventricular myocardium. Biochem Biophys Res Commun 167(1):123-129. doi: 0006-291X(90)91739-F

33. Kaumann A, Semmler AB, Molenaar P (2007) The effects of both noradrenaline and CGP12177, mediated through human beta1adrenoceptors, are reduced by PDE3 in human atrium but PDE4 in CHO cells. Naunyn Schmiedebergs Arch Pharmacol 375(2): 123-131. doi:10.1007/s00210-007-0140-3

34. Kaumann AJ, Galindo-Tovar A, Escudero E, Vargas ML (2009) Phosphodiesterases do not limit beta1-adrenoceptor-mediated sinoatrial tachycardia: evidence with PDE3 and PDE4 in rabbits and PDE1-5 in rats. Naunyn Schmiedebergs Arch Pharmacol 380(5):421-430. doi:10.1007/s00210-009-0445-5

35. Kerfant BG, Zhao D, Lorenzen-Schmidt I, Wilson LS, Cai S, Chen SR, Maurice DH, Backx PH (2007) PI3Kgamma is required for PDE4, not PDE3, activity in subcellular microdomains containing the sarcoplasmic reticular calcium ATPase in cardiomyocytes. Circ Res 101(4):400-408. doi:10.1161/CIRCRE SAHA.107.156422

36. Kittleson MM, Minhas KM, Irizarry RA, Ye SQ, Edness G, Breton E, Conte JV, Tomaselli G, Garcia JG, Hare JM (2005) Gene expression analysis of ischemic and nonischemic cardiomyopathy: shared and distinct genes in the development of heart failure. Physiol Genomics 21(3):299-307. doi:10.1152/ physiolgenomics.00255.2004

37. Kostic MM, Erdogan S, Rena G, Borchert G, Hoch B, Bartel S, Scotland G, Huston E, Houslay MD, Krause EG (1997) Altered expression of PDE1 and PDE4 cyclic nucleotide 
phosphodiesterase isoforms in 7-oxo-prostacyclin-preconditioned rat heart. J Mol Cell Cardiol 29(11):3135-3146. doi:10.1006/ jmcc.1997.0544

38. Lee DI, Vahebi S, Tocchetti CG, Barouch LA, Solaro RJ, Takimoto E, Kass DA (2010) PDE5A suppression of acute beta-adrenergic activation requires modulation of myocyte beta- 3 signaling coupled to PKG-mediated troponin I phosphorylation. Basic Res Cardiol 105(3):337-347. doi:10.1007/s00395-010-0084-5

39. Lehnart SE, Wehrens XH, Reiken S, Warrier S, Belevych AE, Harvey RD, Richter W, Jin SL, Conti M, Marks AR (2005) Phosphodiesterase 4D deficiency in the ryanodine-receptor complex promotes heart failure and arrhythmias. Cell 123(1):2535. doi:10.1016/j.cell.2005.07.030

40. Leineweber K, Bohm M, Heusch G (2006) Cyclic adenosine monophosphate in acute myocardial infarction with heart failure: slayer or savior? Circulation 114(5):365-367. doi:10.1161/ CIRCULATIONAHA.106.642132

41. Leroy J, Abi-Gerges A, Nikolaev VO, Richter W, Lechene P, Mazet JL, Conti M, Fischmeister R, Vandecasteele G (2008) Spatiotemporal dynamics of beta-adrenergic cAMP signals and L-type $\mathrm{Ca}^{2+}$ channel regulation in adult rat ventricular myocytes: role of phosphodiesterases. Circ Res 102(9):1091-1100. doi: 10.1161/CIRCRESAHA.107.167817

42. Levy FO, Qvigstad E, Krobert KA, Skomedal T, Osnes JB (2008) Effects of serotonin in failing cardiac ventricle: signalling mechanisms and potential therapeutic implications. Neuropharmacology 55(6):1066-1071. doi:10.1016/j.neuropharm.2008.07. 010

43. Lissandron V, Zaccolo M (2006) Compartmentalized cAMP/ PKA signalling regulates cardiac excitation-contraction coupling. J Muscle Res Cell Motil 27(5-7):399-403. doi:10.1007/ s10974-006-9077-2

44. Lohse MJ, Engelhardt S, Eschenhagen T (2003) What is the role of beta-adrenergic signaling in heart failure? Circ Res 93(10):896-906. doi:10.1161/01.RES.0000102042.83024.CA

45. Lu Z, Xu X, Hu X, Lee S, Traverse JH, Zhu G, Fassett J, Tao Y, Zhang P, dos Remedios C, Pritzker M, Hall JL, Garry DJ, Chen Y (2010) Oxidative stress regulates left ventricular PDE5 expression in the failing heart. Circulation 121(13):1474-1483. doi: 10.1161/CIRCULATIONAHA.109.906818

46. Lugnier C, Muller B, Le Bec A, Beaudry C, Rousseau E (1993) Characterization of indolidan- and rolipram-sensitive cyclic nucleotide phosphodiesterases in canine and human cardiac microsomal fractions. J Pharmacol Exp Ther 265(3):1142-1151

47. Masunaga R, Nagasaka A, Sawai Y, Hayakawa N, Nakai A, Hotta K, Kato Y, Hishida H, Takahashi H, Naka M, Shimada Y, Tanaka T, Hidaka H, Itoh M (2004) Changes in cyclic nucleotide phosphodiesterase activity and calmodulin concentration in heart muscle of cardiomyopathic hamsters. J Mol Cell Cardiol 37(3):767-774. doi:10.1016/j.yjmcc.2004.06.013

48. McCahill A, Campbell L, McSorley T, Sood A, Lynch MJ, Li X, Yan C, Baillie GS, Houslay MD (2008) In cardiac myocytes, cAMP elevation triggers the down-regulation of transcripts and promoter activity for cyclic AMP phosphodiesterase-4A10 (PDE4A10). Cell Signal 20(11):2071-2083. doi:10.1016/j. cellsig.2008.07.017

49. McConnachie G, Langeberg LK, Scott JD (2006) AKAP signaling complexes: getting to the heart of the matter. Trends Mol Med 12(7):317-323. doi:10.1016/j.molmed.2006.05.008

50. Mongillo M, McSorley T, Evellin S, Sood A, Lissandron V, Terrin A, Huston E, Hannawacker A, Lohse MJ, Pozzan T, Houslay MD, Zaccolo M (2004) Fluorescence resonance energy transfer-based analysis of cAMP dynamics in live neonatal rat cardiac myocytes reveals distinct functions of compartmentalized phosphodiesterases. Circ Res 95(1):67-75. doi:10.1161/01.RES. 0000134629.84732 .11
51. Movsesian MA, Bristow MR (2005) Alterations in cAMP-mediated signaling and their role in the pathophysiology of dilated cardiomyopathy. Curr Top Dev Biol 68:25-48. doi:10.1016/ S0070-2153(05)68002-7

52. Movsesian MA, Bristow MR, Krall J (1989) $\mathrm{Ca}^{2+}$ uptake by cardiac sarcoplasmic reticulum from patients with idiopathic dilated cardiomyopathy. Circ Res 65(4):1141-1144

53. Movsesian MA, Smith CJ, Krall J, Bristow MR, Manganiello VC (1991) Sarcoplasmic reticulum-associated cyclic adenosine $5^{\prime}$ monophosphate phosphodiesterase activity in normal and failing human hearts. J Clin Invest 88(1):15-19. doi:10.1172/JCI115272

54. Muller B, Lugnier C, Stoclet JC (1990) Involvement of rolipramsensitive cyclic AMP phosphodiesterase in the regulation of cardiac contraction. J Cardiovasc Pharmacol 16(5):796-803

55. Munshi A, Kaul S (2008) Stroke genetics-focus on PDE4D gene. Int J Stroke 3(3):188-192. doi:10.1111/j.1747-4949.2008. 00199.x

56. Murthy KS, Zhou H, Makhlouf GM (2002) PKA-dependent activation of PDE3A and PDE4 and inhibition of adenylyl cyclase V/VI in smooth muscle. Am J Physiol Cell Physiol 282(3):C508-C517. doi:10.1152/ajpcell.00373.2001

57. Osadchii OE (2007) Myocardial phosphodiesterases and regulation of cardiac contractility in health and cardiac disease. Cardiovasc Drugs Ther 21(3):171-194. doi:10.1007/s10557007-6014-6

58. Perry SJ, Baillie GS, Kohout TA, McPhee I, Magiera MM, Ang KL, Miller WE, McLean AJ, Conti M, Houslay MD, Lefkowitz RJ (2002) Targeting of cyclic AMP degradation to beta 2adrenergic receptors by beta-arrestins. Science 298(5594):834836. doi:10.1126/science. 1074683

59. Podzuweit T, Nennstiel P, Muller A (1995) Isozyme selective inhibition of cGMP-stimulated cyclic nucleotide phosphodiesterases by erythro-9-(2-hydroxy-3-nonyl) adenine. Cell Signal 7(7):733-738. doi:089865689500042N

60. Pokreisz P, Vandenwijngaert S, Bito V, Van den Bergh A, Lenaerts I, Busch C, Marsboom G, Gheysens O, Vermeersch P, Biesmans L, Liu X, Gillijns H, Pellens M, Van Lommel A, Buys E, Schoonjans L, Vanhaecke J, Verbeken E, Sipido K, Herijgers P, Bloch KD, Janssens SP (2009) Ventricular phosphodiesterase5 expression is increased in patients with advanced heart failure and contributes to adverse ventricular remodeling after myocardial infarction in mice. Circulation 119(3):408-416. doi: 10.1161/CIRCULATIONAHA.108.822072

61. Raeburn D, Underwood SL, Lewis SA, Woodman VR, Battram $\mathrm{CH}$, Tomkinson A, Sharma S, Jordan R, Souness JE, Webber SE et al (1994) Anti-inflammatory and bronchodilator properties of RP 73401, a novel and selective phosphodiesterase type IV inhibitor. Br J Pharmacol 113(4):1423-1431

62. Rena G, Begg F, Ross A, MacKenzie C, McPhee I, Campbell L, Huston E, Sullivan M, Houslay MD (2001) Molecular cloning, genomic positioning, promoter identification, and characterization of the novel cyclic amp-specific phosphodiesterase PDE4A10. Mol Pharmacol 59(5):996-1011

63. Richter W, Day P, Agrawal R, Bruss MD, Granier S, Wang YL, Rasmussen SG, Horner K, Wang P, Lei T, Patterson AJ, Kobilka B, Conti M (2008) Signaling from beta1- and beta2-adrenergic receptors is defined by differential interactions with PDE4. EMBO J 27(2):384-393. doi:10.1038/sj.emboj.7601968

64. Richter W, Jin SL, Conti M (2005) Splice variants of the cyclic nucleotide phosphodiesterase PDE4D are differentially expressed and regulated in rat tissue. Biochem $\mathbf{J}$ 388(Pt 3):803-811. doi: $10.1042 / B J 20050030$

65. Rochais F, Abi-Gerges A, Horner K, Lefebvre F, Cooper DM, Conti M, Fischmeister R, Vandecasteele G (2006) A specific pattern of phosphodiesterases controls the cAMP signals generated by different Gs-coupled receptors in adult rat ventricular 
myocytes. Circ Res 98(8):1081-1088. doi:10.1161/01.RES. 0000218493.09370.8e

66. Salazar NC, Chen J, Rockman HA (2007) Cardiac GPCRs: GPCR signaling in healthy and failing hearts. Biochim Biophys Acta 1768(4):1006-1018. doi:10.1016/j.bbamem.2007.02.010

67. Sato N, Asai K, Okumura S, Takagi G, Shannon RP, FujitaYamaguchi Y, Ishikawa Y, Vatner SF, Vatner DE (1999) Mechanisms of desensitization to a PDE inhibitor (milrinone) in conscious dogs with heart failure. Am J Physiol 276(5 Pt 2): H1699-H1705

68. Shahid M, Nicholson CD (1990) Comparison of cyclic nucleotide phosphodiesterase isoenzymes in rat and rabbit ventricular myocardium: positive inotropic and phosphodiesterase inhibitory effects of Org 30029, milrinone and rolipram. Naunyn Schmiedebergs Arch Pharmacol 342(6):698-705

69. Silver PJ, Allen P, Etzler JH, Hamel LT, Bentley RG, Pagani ED (1990) Cellular distribution and pharmacological sensitivity of low $\mathrm{Km}$ cyclic nucleotide phosphodiesterase isozymes in human cardiac muscle from normal and cardiomyopathic subjects. Second Messengers Phosphoproteins 13(1):13-25

70. Smith CJ, Huang R, Sun D, Ricketts S, Hoegler C, Ding JZ, Moggio RA, Hintze TH (1997) Development of decompensated dilated cardiomyopathy is associated with decreased gene expression and activity of the milrinone-sensitive cAMP phosphodiesterase PDE3A. Circulation 96(9):3116-3123

71. Steinfath M, Danielsen W, von der Leyen H, Mende U, Meyer W, Neumann J, Nose M, Reich T, Schmitz W, Scholz H et al (1992) Reduced alpha 1- and beta 2-adrenoceptor-mediated positive inotropic effects in human end-stage heart failure. Br J Pharmacol 105(2):463-469

72. Terrin A, Di Benedetto G, Pertegato V, Cheung YF, Baillie G, Lynch MJ, Elvassore N, Prinz A, Herberg FW, Houslay MD, Zaccolo M (2006) PGE(1) stimulation of HEK293 cells generates multiple contiguous domains with different [cAMP]: role of compartmentalized phosphodiesterases. J Cell Biol 175(3): 441-451. doi:10.1083/jcb.200605050

73. Ukita T, Sugahara M, Terakawa Y, Kuroda T, Wada K, Nakata A, Ohmachi Y, Kikkawa H, Ikezawa K, Naito K (1999) Novel, potent, and selective phosphodiesterase-4 inhibitors as antiasthmatic agents: synthesis and biological activities of a series of 1pyridylnaphthalene derivatives. J Med Chem 42(6):1088-1099. doi:10.1021/jm9803141

74. Usta C, Puddu PE, Papalia U, De Santis V, Vitale D, Tritapepe L, Mazzesi G, Miraldi F, Ozdem SS (2004) Comparison of the inotropic effects of levosimendan, rolipram, and dobutamine on human atrial trabeculae. J Cardiovasc Pharmacol 44(5):622-625. doi:00005344-200411000-00017

75. Vandeput F, Krall J, Ockaili R, Salloum FN, Florio V, Corbin JD, Francis SH, Kukreja RC, Movsesian MA (2009) cGMP-hydrolytic activity and its inhibition by sildenafil in normal and failing human and mouse myocardium. J Pharmacol Exp Ther 330(3):884-891. doi:10.1124/jpet.109.154468

76. Vandeput F, Wolda SL, Krall J, Hambleton R, Uher L, McCaw KN, Radwanski PB, Florio V, Movsesian MA (2007) Cyclic nucleotide phosphodiesterase PDE1C1 in human cardiac myocytes. J Biol Chem 282(45):32749-32757. doi:10.1074/jbc. M703173200

77. Vargas ML, Hernandez J, Kaumann AJ (2006) Phosphodiesterase PDE3 blunts the positive inotropic and cyclic AMP enhancing effects of CGP12177 but not of noradrenaline in rat ventricle. $\mathrm{Br}$ J Pharmacol 147(2):158-163. doi:10.1038/sj.bjp.0706498

78. von der Leyen H, Mende U, Meyer W, Neumann J, Nose M, Schmitz W, Scholz H, Starbatty J, Stein B, Wenzlaff H et al (1991) Mechanism underlying the reduced positive inotropic effects of the phosphodiesterase III inhibitors pimobendan, adibendan and saterinone in failing as compared to nonfailing human cardiac muscle preparations. Naunyn Schmiedebergs Arch Pharmacol 344(1):90-100

79. Weishaar RE, Burrows SD, Kobylarz DC, Quade MM, Evans DB (1986) Multiple molecular forms of cyclic nucleotide phosphodiesterase in cardiac and smooth muscle and in platelets. Isolation, characterization, and effects of various reference phosphodiesterase inhibitors and cardiotonic agents. Biochem Pharmacol 35 (5):787-800. doi:0006-2952(86)90247-9

80. Weishaar RE, Kobylarz-Singer D, Klinkefus BA (1989) New mechanisms for positive inotropic agents: focus on the discovery and development of imazodan. Cardiovasc Drugs Ther 3(1): 29-42

81. Weishaar RE, Kobylarz-Singer DC, Kaplan HR (1987) Subclasses of cyclic AMP phosphodiesterase in cardiac muscle. J Mol Cell Cardiol 19(10):1025-1036. doi:S0022-2828(87)80574-6

82. Weishaar RE, Kobylarz-Singer DC, Steffen RP, Kaplan HR (1987) Subclasses of cyclic AMP-specific phosphodiesterase in left ventricular muscle and their involvement in regulating myocardial contractility. Circ Res 61(4):539-547

83. Xiang Y, Kobilka BK (2003) Myocyte adrenoceptor signaling pathways. Science 300(5625):1530-1532. doi:10.1126/science. 1079206

84. Xiang Y, Naro F, Zoudilova M, Jin SL, Conti M, Kobilka B (2005) Phosphodiesterase 4D is required for beta2 adrenoceptor subtype-specific signaling in cardiac myocytes. Proc Natl Acad Sci USA 102(3):909-914. doi:10.1073/pnas.0405263102

85. Xiao RP, Zhu W, Zheng M, Chakir K, Bond R, Lakatta EG, Cheng H (2004) Subtype-specific beta-adrenoceptor signaling pathways in the heart and their potential clinical implications. Trends Pharmacol Sci 25(7):358-365. doi:10.1016/j.tips.2004. 05.007

86. Yan C, Miller CL, Abe J (2007) Regulation of phosphodiesterase 3 and inducible cAMP early repressor in the heart. Circ Res 100(4):489-501. doi:10.1161/01.RES.0000258451.44949.d7 